\title{
MICROLEAKAGE EVALUATION OF GLASS CARBOMER CEMENT WITH AND WITHOUT SURFACE COAT IN PRIMARY MOLARS (IN VITRO STUDY)
}

\author{
Amr Hassan*, Magda El Tekeya**, Seham A Hanafy ${ }^{* * *}$ and Dalia AM Talaat ${ }^{* * * *}$
}

\begin{abstract}
Aim: To evaluate the microleakage of the glass carbomer cement with and without protective surface coat in primary molars and to compare it to conventional glass ionomer cement.

Materials and Methods: Forty sound primary molars were included in the study. They were divided into two groups $(\mathrm{n}=20)$ according to the restorative material tested. Group A (experimental group): Teeth were restored using glass carbomer cement, and group B (control group): Teeth were restored using conventional glass ionomer cement. Then each group was further subdivided into two sub-groups according to the presence of surface coat. After teeth restoration, they were immersed in methylene blue solution for 24 hours then they were sectioned longitudinally into two equal halves and tested for microleakage.
\end{abstract}

Results: There was a statistically significant difference between the microleakage scores of glass carbomer cement with surface coat (sub-group A1) and without protective surface coat (sub-group A2) in favor of sub-group A1. However, there was no statistically significant difference between the microleakage scores of conventional glass ionomer cement with surface coat (sub-group B1) and without protective surface coat (sub-group B2). By comparing the 4 sub-groups, sub-group A1 showed the lowest microleakage score, while sub-group A2 showed the highest score with statistically significant difference.

Conclusion: Surface coat when added to the glass carbomer cement yields less microleakage than the unsealed glass carbomer and conventional GIC.

KEYWORDS: Glass carbomer cement, Conventional glass ionomer cement, Microleakage.

* MSc in Pediatric Dentistry, Department of Pediatric Dentistry and Dental Public Health, Faculty of Dentistry, Alexandria University.

** Professor of Pediatric Dentistry, Department of Pediatric Dentistry and Dental Public Health, Faculty of Dentistry, Alexandria University.

*** Professor of Dental Biomaterials, Department of Dental Biomaterials, Faculty of Dentistry, Alexandria University. **** Lecturer of Pediatric Dentistry, Department of Pediatric Dentistry and Dental Public Health, Faculty of Dentistry, Alexandria University. 


\section{INTRODUCTION}

Dental caries is the most widely spreading disease in children.$^{(1)}$ It is an infectious transmissible bacterial disease characterized by a drop of salivary $\mathrm{pH}$, demineralization of tooth structure and loss of minerals which diffuse out of the tooth. ${ }^{(1)}$ In primary dentition, it remains a considerable health problem due to its rapid progress to the pulp.(2)

Modern restorative care of carious lesions is based on the minimal intervention approach, early prevention and interception. ${ }^{(3,4)}$ The conventional glass ionomer cement (GIC) has been advocated as a restorative material because of its ability to chemically bond to tooth structure and release fluoride. (5) With additional benefits of biocompatibility and antibacterial effect, it has been well accepted in pediatric patients with high caries risk activity. ${ }^{(6)}$

Mclean (7) listed several drawbacks of conventional GIC that limit their indications for permanent restoration in primary teeth. In an attempt to improve their mechanical properties, a variety of modifiers have been added to conventional GIC. The addition of amalgam alloy powder to glass ionomer was expected to increase the strength and provide radio-opacity. ${ }^{(8)}$ Some investigators found no significant difference between the strengths of conventional and metal-reinforced glass ionomers. (9-11) Also, because of the metal additives, metalreinforced cements are not tooth-colored and color ranges from light to dark gray. ${ }^{(12)}$

In the late1980, the addition of polymerizable hydrophilic resin to conventional GIC resulted in the development of resin-modified formulas that set by a dual reaction: the acid-base reaction and a freeradical polymerization process. ${ }^{(13,14)}$

Studies reported that resin modified GICs show better mechanical properties than conventional glass ionomers. Though still their polymerization shrinkage and low wear resistance constitutes major drawbacks. ${ }^{(13,14,15)}$

As radioopacity is required and aesthetics of less importance, a GIC (amalgomer CR) has been introduced aiming to offer the dental profession- als the established benefits of glass ionomers combined with the strength of amalgam. ${ }^{(16)}$ It was the first glass ionomer filling materials to achieve an excess of $300 \mathrm{MPa}$ at 24 hours after placement. The compressive strength of Amalgomer CR continues to increase so that at one month after placement, it achieves $423 \mathrm{MPa}$ which is higher than most composites used for posterior restorations. ${ }^{(17-19)}$ Therefore, amalgomer CR is capable of withstanding all the stresses of the oral environment.

Glass carbomer cement, a GIC-based restorative material, has been introduced with claims of improved physical characteristics. This new material contains carbomised nano-sized powder particles and fluorapatite as secondary filler. The incorporation of nano-sized filler particles into the glass carbomer cement may improve its compressive strength and wear resistance. ${ }^{(20)}$ Moreover, applying a surface coat may also aid in the improvement of surface characteristics and sealing properties of the glass carbomer cement. ${ }^{(21)}$

The selection of a new material should consider the mechanical and physical properties and also its biological compatibility. In addition, a restorative material should provide a long-term hermetic seal against bacterial penetration. This is especially important as microleakage is a common cause of restoration failure and may lead to secondary caries and pulpal irritation. ${ }^{(21,22)}$

As there is few published data on the clinical use of the nano-sized glass carbomer cement, laboratory testing may provide valuable insights into the physical properties of the material, particularly in primary teeth. Consequently, microleakage of glass carbomer cement should be investigated in primary molars. Thus this study aimed to evaluate the microleakage of the glass carbomer cement with and without protective surface coat in primary molars and compare it to conventional GIC. The null hypothesis tested was that no difference in microleakage values between the glass carbomer cement with and without surface coat, also no difference between the sealing efficiency of the glass carbomer cement and the conventional GIC. 


\section{MATERIALS AND METHODS}

\section{Study design}

An experimental in vitro study has been done. It was performed after receiving the approval of the Dental Research Ethics Committee, of the Faculty of Dentistry, Alexandria University.

\section{Sample size}

Sample size was calculated using a power $80 \%$ to detect meaningful difference at microleakage score between four studied sub-groups of extracted primary molars restored by glass carbomer cement with and without surface coat and conventional GIC with and without surface coat $=10.0 \%{ }^{(22)}$ Alpha error $=0.05$ and effect size $=0.96$. The minimum required sample size per sub-group using these assumptions was calculated using Epi- Info software to be $8 .{ }^{(23)}$ This is increased to 10 per sub-group to make up the errors in processing (30\% increase).

\section{Study sample}

Forty primary molars extracted for orthodontic purpose or near their time of exfoliation were collected from public hospitals and outpatients' clinic of Pediatric Dentistry Department, Faculty of Dentistry, Alexandria University. Teeth were cleaned from debris and blood stains, only those that were free from caries, enamel cracks, or structural defects as evident under the microscope at 20x magnification were included in the study. Then they were stored in distilled water at room temperature till required for use.

\section{Materials}

The materials used in this study were glass carbomer cement (Glass Carbomer Products, Leiden, Netherlands), it is composed of Powder: Sodium, calcium alumino fluorosilicate carbomised nanosized particles, shade pigments, ceramic fillers, freeze-dried polycarboxylic acid, tartaric acid and fluoroapatite-hydroxyapatite particles, and liquid: Polyacrylic acid, glass carbomer surface coat (Glass Carbomer Products, Leiden, Netherlands) which is a monomer free silicone based coat, conventional glass ionomer (Ionofil Molar AC Quick. Voco, Cux-haven, Germany), it is composed of: Powder: Sodium, calcium alumino fluorosilicate, shade pigments, and Liquid: Polyacrylic acid (acid in form of copolymer with itaconic, maleic, and tricarboxylic acid), tartaric acid and water, conventional glass ionomer surface coat (Ionofil Molar AC Quick. Voco, Cux-haven, Germany) which contains Bis-GMA, diurethanedimethacrylate, BHT, dentin conditioner that consists of $20 \%$ Polyacrylic acid, light curing system-LED (Ivoclar Vivadent, Germany) and amalgamator (Ivoclar Vivadent, Germany).

\section{Methods}

The teeth included in the study were randomly assigned into 2 main groups ( $\mathrm{n}=20 / \mathrm{each})$ according to the restorative material tested. Group $\mathbf{A}$ (experimental group): Teeth were restored with Glass Carbomer Cement. Group B (control group): Teeth were restored with conventional GIC. Then teeth in each group were further subdivided into 2 sub-groups $(n=10 /$ each $)$ according to the presence of surface coating (SC): Sub-group A1: Glass Carbomer Cement with SC. Sub-group A2: Glass Carbomer Cement without SC. Sub-group B1: Conventional GIC with SC. Sub-group B2: Conventional GIC without SC.

\section{Teeth mounting}

The self-acrylic resin was mixed and poured into split cuboidal copper moulds $(2 \mathrm{~cm}$ in diameter and $3 \mathrm{~cm}$ in height), then each tooth was embedded with its occlusal surface facing upwards and perpendicular to the long axis of the block.

\section{Cavity preparation}

Standardized Class I cavities for resin restorations were prepared in each tooth using \#330 carbide burs, replaced every four preparation, at high speed with air/water cooled hand piece. ${ }^{(24)}$ Class I cavity was considered the most appropriate cavity design for evaluating microleakage. ${ }^{(25)}$ Feilzer et al (26) found that according to cavity configuration in 
Class I cavities, the number of bonded surfaces to unbonded surface greater than any other cavity. In addition this cavity design allows the detection of linear microleakage at the occlusal cavity wall.

\section{Teeth restoration}

For all prepared cavities, cavity conditioner (20\% polyacrylic acid) was applied to the surfaces by a micro-brush; left undisturbed for 10 seconds; then the cavity was rinsed with water spray for 10 seconds and gently dried using oil-free compressed air for 5 seconds. ${ }^{(27)}$ Removing the smear layer and cleaning the tooth facilitate a chemical bond between the glass inonomer and the dental hard tissue and enhance the lock, so reduce the microleakage. ${ }^{(28)}$ If the smear layer is not removed, it can acts as a weak point leading to cohesive failure during polymerization shrinkage and episodes of thermal expansion and contraction. ${ }^{(29)}$ For group A: Glass carbomer cement capsule was mixed by amalgamator for 10-15 seconds; then it was injected into the cavity and left to set 4 minutes. For sub group A1 glass carbomer surface gloss was applied and photo cured for $10 \mathrm{sec}$ by using LED light curing system. For group B: Conventional GIC was mixed by amalgamator for 10 seconds; then it was injected into the cavity and left to set 4 minutes. For subgroup B1 surface coat was applied and photo cured for $10 \mathrm{sec}$ by using LED light curing system. The restorative materials were condensed into the corners of the cavities using a ball burnisher. All steps were done according to manufacturer's recommendation. Restorations were finished and polished immediately after final setting with extra fine friction grip diamond bur and rubber cup under water cooling system.

\section{Storage}

Teeth included in the study were stored in distilled water at $37^{\circ} \mathrm{C}$ inside an incubator unit (VEB MLW Dental Fabrik Teffurt, BST5020. Germany) for 24 hours to be prepared for thermocycling. Thermocycling was done in a water bath for 1000 cycles using the thermocycling machine (VEB MLW Dental Fabrik Teffurt, BST5020. Germany) alternating between $5^{\circ} \mathrm{C}$ and $55^{\circ} \mathrm{C}$ with a dwell time 30 seconds to simulate the oral condition. ${ }^{(30)}$ The use of thermocycling highlights the mismatch in the thermal coefficient of expansion between the restoration and tooth structure, which would result in repeated expansion-contraction stresses at the tooth-restoration interface leading to gap formation and microleakage..$^{(31)}$

\section{Microleakage test}

Teeth surfaces were coated with three layers of nail polish except at a $1 \mathrm{~mm}$ wide window surrounding the margins of the restorations, which standardized using a template $1 \mathrm{~mm}$ more than the restoration dimensions. This to ensure a proof isolation of the teeth surfaces against dye penetration. ${ }^{(32)}$ Teeth were immersed in $2 \%$ methylene blue solution in small dark closed bottles away from sunlight for 24 hours. Aqueous methylene blue solution was prepared by adding $50 \mathrm{~g}$ of methylene blue salt to $100 \mathrm{ml}$ deionized water. The solution was shaken for 3 minutes to homogenize. Finally, teeth were rinsed thoroughly under running water for half an hour and were then sectioned longitudinally in a mesiodistal direction parallel to the long axis through the center of the restoration using a watercooled low-speed diamond saw that was replaced every 5 specimens. ${ }^{27,33)}$ The sectioning resulted in two approximately equal parts which where both analyzed for microleakage.

\section{Evaluation}

The cut surfaces of the sectioned teeth were examined for dye penetration and viewed under light stereomicroscope (OLYMPUS stereoscope SZ1 1.Olympus Optical Co.Ltd. 2-43-2, Hatagaya, Shibuya - Ku, Tokyo, Japan) at a magnification of $\mathrm{x} 20$. The dye leakage method was used in this study because it is simple, inexpensive; do not require the use of complex laboratory equipment and their contrasting color. Also, being organic avoided its chemical reaction or any destruction to 
the specimens. ${ }^{(34,35)}$ The extent of dye penetration at occlusal margins of the restorations was assessed according to the scoring system described by Parbhakar et al. ${ }^{(36)}$ (Table 1)

TABLE (1) Scoring for dye penetration for marginal microleakage on the occlusal wall

\begin{tabular}{|l|l|}
\hline Score & Criteria \\
\hline $\mathbf{0}$ & No dye penetration. \\
\hline $\mathbf{1}$ & Dye penetration into enamel only. \\
\hline $\mathbf{2}$ & $\begin{array}{l}\text { Dye penetration between the restoration and } \\
\text { the tooth in the enamel and dentin. }\end{array}$ \\
\hline $\mathbf{3}$ & Dye penetration into the pulpal chamber. \\
\hline
\end{tabular}

Both sections were scored and the section with the greatest amount of microleakage occlusally was recorded as the score of the restoration. Moreover, samples were evaluated blindly by two independent examiners. The intra and inter examiner reliability to evaluate the degree of dye penetration were assessed using Kappa statistic. The kappa statistic of intra examiner reliability was 0.887 which indicated consistency of the examiner in the application of scoring criteria over time and 0.842 for inter examiner reliability which indicated strong agreement between the examiners.

\section{Statistical Methodology}

Data were fed to the computed and analyzed using IBM-SPSS software package version 20.0. ${ }^{(37)}$ Qualitative data were described using number and percent. Quantitative data were described using range (minimum and maximum) mean, standard deviation and median. The distributions of quantitative variables were tested for normality using Kolmogorov- Smirnov test, Shapiro- Wilk test and D' Agstino test. The data were ordinal Quantitative depending on the scale of microleakage scores so non- parametric tests were used. Comparison between the different study groups were done using Mann- Whitney test. Significance of the obtained results was judged at the $5 \%$ level. ${ }^{(38)}$

\section{RESULTS}

By comparing between the microleakage scores at occlusal margins for glass carbomer cement with surface coat (sub-group A1) and without protective surface coat (sub-group A2), there was statistically significant difference between the two sub-groups in favor of sub-group A1 $(\mathrm{P}<0.05)$. (Table 2)

TABLE (2) Comparison between the microleakage scores at occlusal margins for the glass carbomer cement with and without protective surface coat (experimental group A)

\begin{tabular}{|c|c|c|c|c|}
\hline & \multicolumn{2}{|c|}{$\begin{array}{c}\text { Sub-group A1 } \\
\text { (Glass carbomer } \\
\text { with coat) } \\
\text { Experimental } \\
\text { group } \\
(\mathbf{n}=10)\end{array}$} & \multicolumn{2}{|c|}{$\begin{array}{c}\text { Sub-group A2 } \\
\text { (Glass carbomer } \\
\text { without coat) } \\
\text { Experimental } \\
\text { group } \\
(\mathrm{n}=\mathbf{1 0})\end{array}$} \\
\hline & No. & $\%$ & No. & $\%$ \\
\hline \multicolumn{5}{|c|}{ Microleakage score } \\
\hline 0 & 4 & 40.0 & 0 & 0.0 \\
\hline 1 & 6 & 60.0 & 0 & 0.0 \\
\hline 2 & 0 & 0.0 & 9 & 90.0 \\
\hline 3 & 0 & 0.0 & 1 & 10.0 \\
\hline Min. - Max. & \multicolumn{2}{|c|}{$0.0-1.0$} & \multicolumn{2}{|c|}{$2.0-3.0$} \\
\hline Mean \pm SD & \multicolumn{2}{|c|}{$0.60 \pm 0.52$} & \multicolumn{2}{|c|}{$2.10 \pm 0.32$} \\
\hline Median & \multicolumn{2}{|c|}{1.0} & \multicolumn{2}{|c|}{2.0} \\
\hline $\mathbf{Z}(\mathbf{p})$ & \multicolumn{4}{|c|}{$4.038^{*}\left(<0.001^{*}\right)$} \\
\hline
\end{tabular}

Z: Z for Mann Whitney test

$*$ : Statistically significant at $p \leq 0.05$

Regarding the microleakage scores at occlusal margins for conventional GIC with surface coat (sub-group B1) and without protective surface coat (sub-group B2) there was no significant difference between the two sub-groups ( $\mathrm{P}>0.05)$. (Table 3 )

The Comparison between the four study subgroups according to microleakage scores at occlusal margins revealed that the mean microleakage for sub-group A1exibited the lowest score $0.60 \pm$ 0.52 , while the mean microleakage for sub-group A2 exhibited the highest score $2.10 \pm 0.32$. Using Chi square for Kruskal-Wallis test (nonparametric ANOVA), there was statistical significant difference between 4 sub-groups $(\mathrm{p}<0.05)$ in microleakage 
scores at occlusal margins. Using Mann Whitney for comparing between glass carbomer with coat (sub-group A1) and each other subgroup, there was statistical significant difference in favor to subgroup A1 ( $\mathrm{p}<0.05)$. Also by comparing between glass carbomer without coat (sub- group A2) and each other group, there was statistical significant difference in favor to the other 3 study sub-groups ( $\mathrm{p}$ $<0.05)$. While, no statistically significant difference has been found between conventional GIC with coat (sub-group B1) and conventional GIC without coat (sub-group B2) $(\mathrm{P}>0.05)$. (Table 4)

TABLE (3) Comparison between the microleakage score at occlusal margins for the conventional glass ionmer with and without protective surface coat (control group B)

\begin{tabular}{|c|c|c|c|c|}
\hline & \multicolumn{2}{|c|}{$\begin{array}{c}\text { Sub-group B1 (Conventional GIC with coat) } \\
\text { Control group }(n=10)\end{array}$} & \multicolumn{2}{|c|}{$\begin{array}{c}\text { Sub-group B2 (Conventional GIC without coat) } \\
\text { Control group }(n=10)\end{array}$} \\
\hline & No. & $\%$ & No. & $\%$ \\
\hline \multicolumn{5}{|c|}{ Microleakage score } \\
\hline 0 & 0 & 0.0 & 0 & 0.0 \\
\hline 1 & 7 & 70.0 & 5 & 50.0 \\
\hline 2 & 3 & 30.0 & 5 & 50.0 \\
\hline 3 & 0 & 0.0 & 0 & 0.0 \\
\hline Min. - Max. & \multicolumn{2}{|c|}{$1.0-2.0$} & \multicolumn{2}{|c|}{$1.0-2.0$} \\
\hline Mean \pm SD. & \multicolumn{2}{|c|}{$1.30 \pm 0.48$} & \multicolumn{2}{|c|}{$1.50 \pm 0.53$} \\
\hline Median & \multicolumn{2}{|c|}{1.0} & \multicolumn{2}{|c|}{1.50} \\
\hline $\mathbf{Z}(\mathbf{p})$ & \multicolumn{4}{|c|}{$0.890(0.374)$} \\
\hline
\end{tabular}

\section{Z: Z for Mann Whitney test.}

TABLE (4) Comparison between the four sub-groups according to microleakage score.

\begin{tabular}{|c|c|c|c|c|c|c|c|c|}
\hline & \multicolumn{2}{|c|}{$\begin{array}{c}\text { (Glass carbomer with coat) } \\
\text { Sub-group A1 } \\
\text { Experimental group } \\
(\mathrm{n}=10)\end{array}$} & \multicolumn{2}{|c|}{$\begin{array}{c}\text { (Glass carbomer without } \\
\text { coat) Sub-group A2 } \\
\text { Experimental group } \\
(\mathrm{n}=10)\end{array}$} & \multicolumn{2}{|c|}{$\begin{array}{c}\text { (Conventional GIC with } \\
\text { coat) Sub-group B1 } \\
\text { Control group } \\
(\mathrm{n}=10)\end{array}$} & \multicolumn{2}{|c|}{$\begin{array}{c}\text { (Conventional GIC without } \\
\text { coat) Sub-group B2 } \\
\text { Control group } \\
(\mathrm{n}=10)\end{array}$} \\
\hline & No. & $\%$ & No. & $\%$ & No. & $\%$ & No. & $\%$ \\
\hline \multicolumn{9}{|c|}{ Microleakage score } \\
\hline 0 & 4 & 40.0 & 0 & 0.0 & 0 & 0.0 & 0 & 0.0 \\
\hline 1 & 6 & 60.0 & 0 & 0.0 & 7 & 70.0 & 5 & 50.0 \\
\hline 2 & 0 & 0.0 & 9 & 90.0 & 3 & 30.0 & 5 & 50.0 \\
\hline 3 & 0 & 0.0 & 1 & 10.0 & 0 & 0.0 & 0 & 0.0 \\
\hline Min. - Max. & \multicolumn{2}{|c|}{$0.0-1.0$} & \multicolumn{2}{|c|}{$2.0-3.0$} & \multicolumn{2}{|c|}{$1.0-2.0$} & \multicolumn{2}{|c|}{$1.0-2.0$} \\
\hline Mean \pm SD & \multicolumn{2}{|c|}{$0.60 \pm 0.52$} & \multicolumn{2}{|c|}{$2.10 \pm 0.32$} & \multicolumn{2}{|c|}{$1.30 \pm 0.48$} & \multicolumn{2}{|c|}{$1.50 \pm 0.53$} \\
\hline Median & \multicolumn{2}{|c|}{1.0} & \multicolumn{2}{|c|}{2.0} & \multicolumn{2}{|c|}{1.0} & \multicolumn{2}{|c|}{1.50} \\
\hline${ }^{\mathrm{KW}} \chi^{2}(\mathbf{p})$ & \multicolumn{8}{|c|}{$23.408^{*}\left(<0.001^{*}\right)$} \\
\hline $\mathbf{p}_{1}$ & & & \multicolumn{2}{|c|}{$<0.001^{*}$} & \multicolumn{2}{|c|}{$0.010^{*}$} & \multicolumn{2}{|c|}{$0.003^{*}$} \\
\hline $\mathbf{p}_{2}$ & & & & & \multicolumn{2}{|c|}{$0.004^{*}$} & \multicolumn{2}{|c|}{$0.010^{*}$} \\
\hline $\mathbf{p}_{3}$ & & & & & & & & \\
\hline
\end{tabular}

${ }^{k}{ }^{2}{ }^{2}$ : Chi square for Kruskal Wallis test

*: Statistically significant at $\mathbf{p} \leq \mathbf{0 . 0 5}$

$p_{1}: p$ value for Mann Whitney for comparing between carbomer with coat and each other group

$p_{2}: p$ value for Mann Whitney for comparing between carbomer without coat and each other group

$p_{3}: p$ value for Mann Whitney for comparing between conventional GIC with coat and conventional GIC without coat 


\section{Stereomicroscope Evaluation}

The depth of dye penetration is shown in figures 1-8.

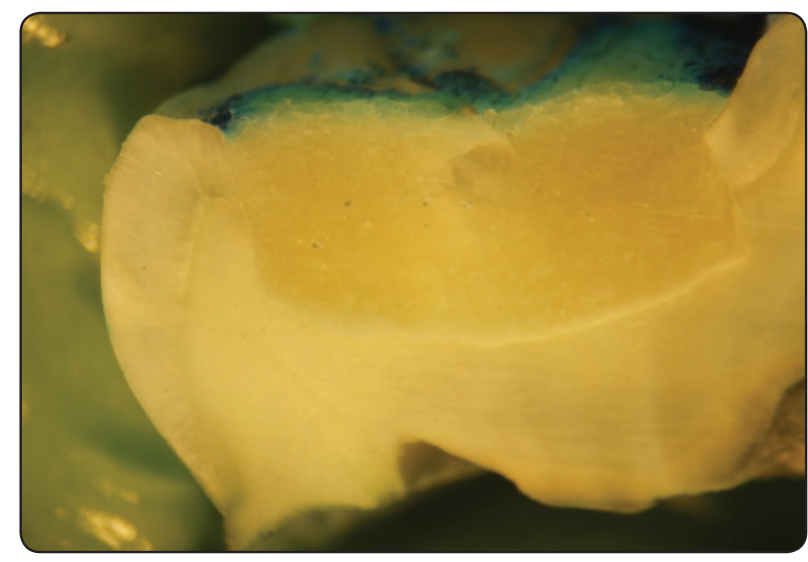

Fig. (1) Specimen from subgroup A1 (glass carbomer with coat) showing microleakage score 0 at occlusal margin $(20 \mathrm{x})$.

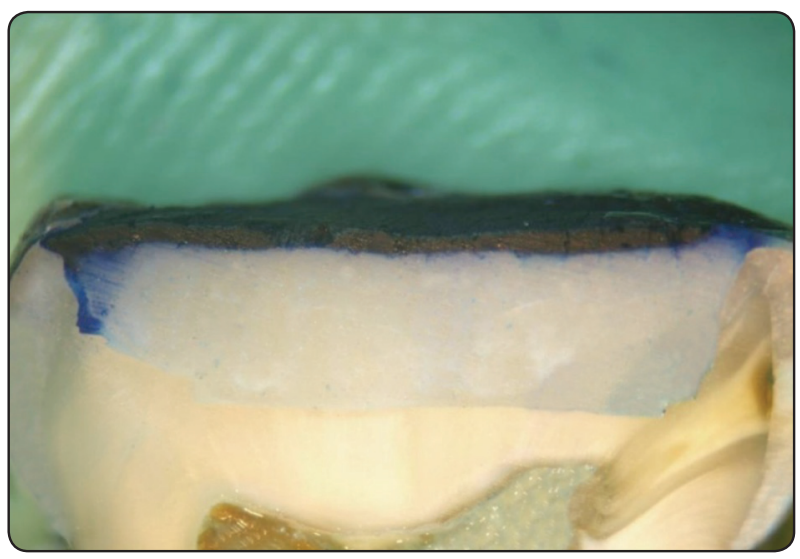

Fig. (3) Specimen from subgroup A2 (glass carbomer without coat) showing microleakage score 2 at occlusal margin (20x).

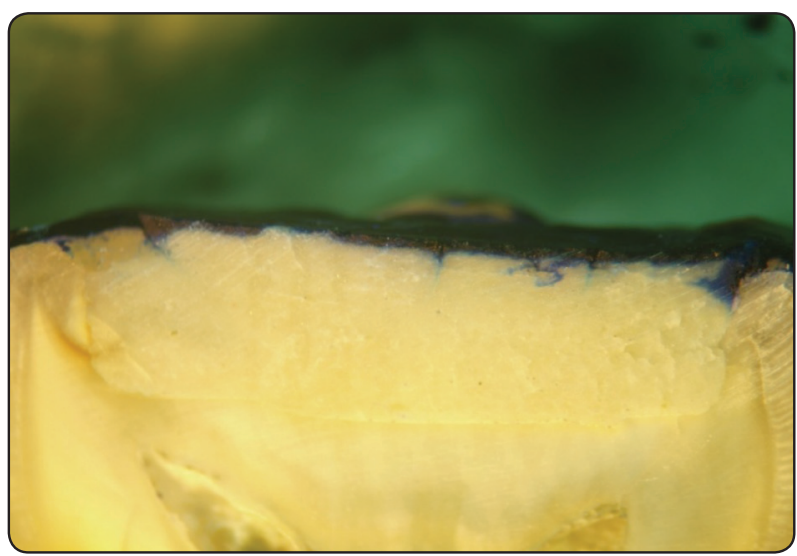

Fig. (5) Specimen from subgroupB1 (conventional GIC with coat) showing microleakage score 1 at occlusal margin $(20 \mathrm{x})$.

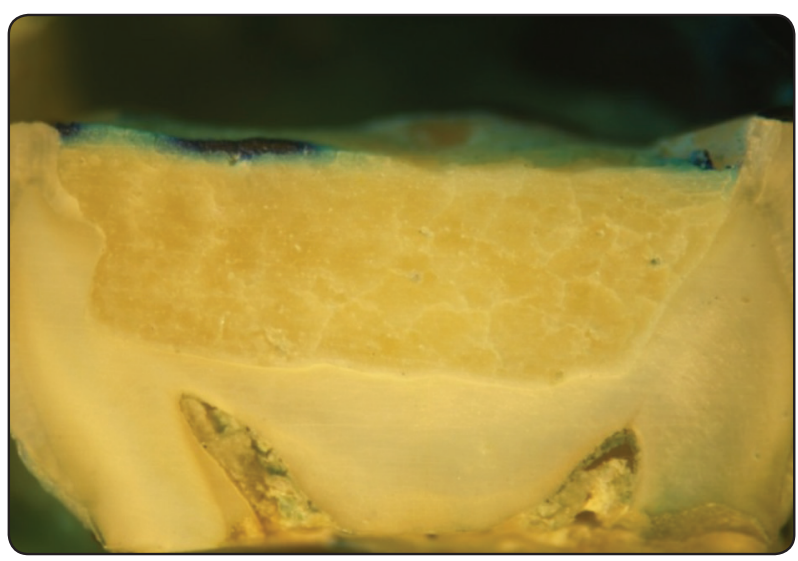

Fig. (2) Specimen from subgroup A1 (glass carbomer with coat) showing microleakage score 1 at occlusal margin $(20 \mathrm{x})$.

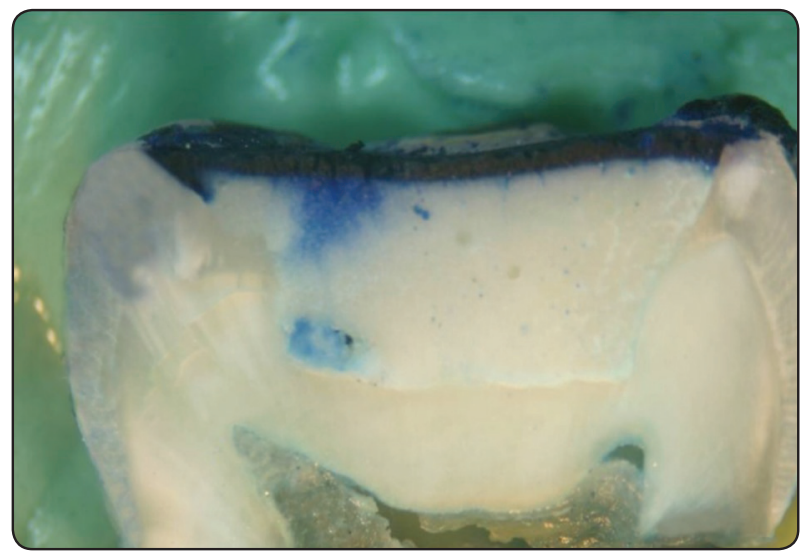

Fig. (4) Specimen from subgroup A2 (glass carbomer without coat) showing microleakage score 3 at occlusal margin (20 x).

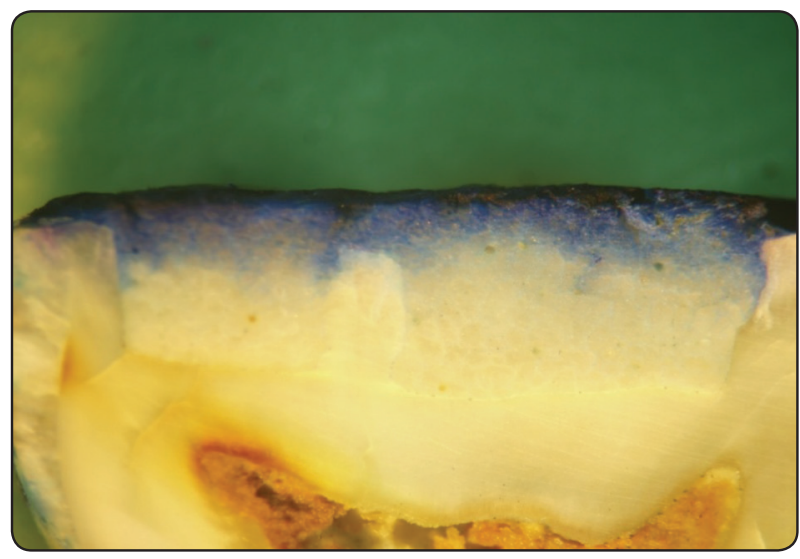

Fig. (6) Specimen from subgroupB1 (conventional GIC with coat) showing microleakage score 2 at occlusal margin $(20 \mathrm{x})$ 


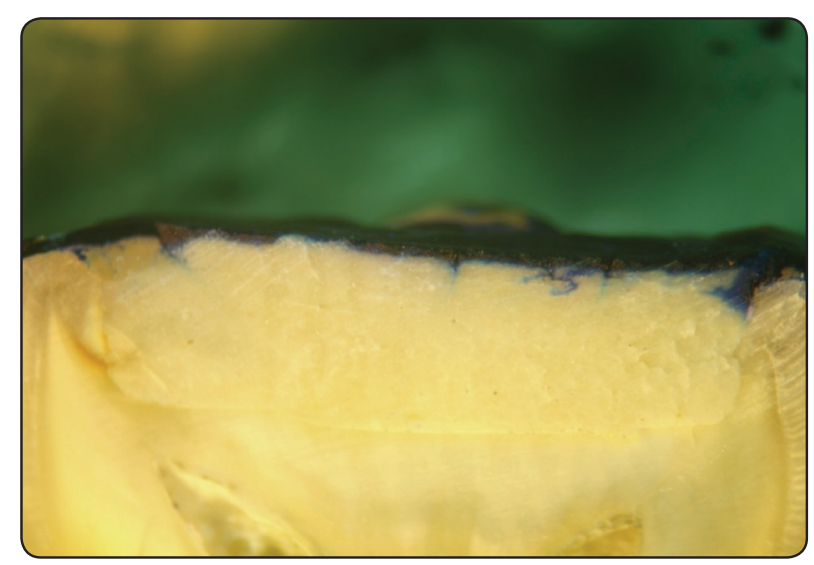

Fig. (7) Specimen from subgroupB2 (conventional GIC without coat) showing microleakage score 1 at occlusal margin $(20 \mathrm{x})$.

\section{DISCUSSION}

Marginal seal plays a major role in the success of dental restorations. Additionally, proper adhesion between the restorative material and the cavity walls results in good marginal sealing with less microleakage and a longer life of the restoration. ${ }^{(39)}$

In the present study, when comparing the glass carbomer cement with and without surface coat there was a significantly lower mean microleakage scores in glass carbomer cement with coat than glass carbomer cement without surface coat, this finding was supported by Cehreli et al. (22) Regarding the evaluation of the surface coat in both sub-groups of conventional GIC, it was revealed that there was no statistically significant difference between them. This finding disagree with Mount et al ${ }^{(40)}$ and Hotta el $\mathrm{al}^{(41)}$ who reported that following the placement of GIC, surface protection must be provided to maintain the water balance of restorations for the first 24 hours and to avoid early solubility of the material.

Moreover, when comparing the four study subgroups, there was a statistically significant difference between them with glass carbomer cement with surface coat showed significantly lower mean microleakage score than conventional

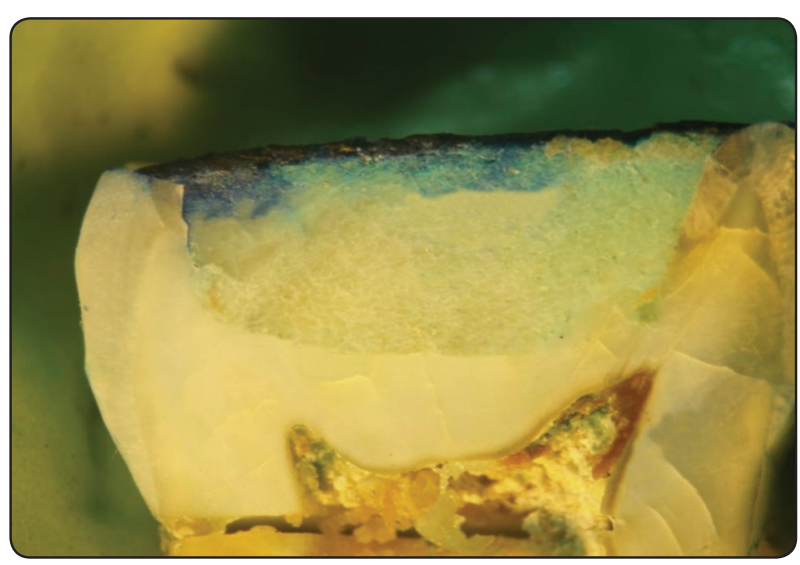

Fig. (8) Specimen from subgroupB2 (conventional GIC without coat) showing microleakage score 2 at occlusal margin (20 x).

GIC with and without protective surface coat, while glass carbomer cement without surface coat showed significantly higher mean microleakage score than conventional GIC with and without protective surface coat. This finding disagrees with Cehreli et al (22) who found no statistically significant difference between coated glass carbomer and coated conventional GIC.

The results of the present study showed that the absence of surface coat reduced the marginal sealing efficiency of both the conventional GIC and the glass carbomer cement, with the latter yielding the greatest amount of microleakage, this was in accordance with Cehreli et al. ${ }^{(22)}$ The inferior sealing characteristics of the glass carbomer in its unsealed state, particularly in comparison with the uncoated glass carbomer may be due to the absence of the wetting effect of the glass carbomer surface gloss which resulted in a rapid deterioration of the material surface and tooth- material interface, leading to increased levels of leakage.

In the coated restorations, the surface gloss used with the glass carbomer cement was more effective in its sealing ability as compared to the resin based surface coating applied to the conventional GIC. Although the manufacture does not provide detailed information regarding how the surface 
gloss acts it is evident that its formulation provides some chemical interaction with the glass carbomer cement leading to better sealing properties on glass carbomer compared to that of the light cure varnish seal on the conventional GIC. ${ }^{21,22)}$

The results of the current study necessitate rejection of the null hypothesis that sealing properties of glass carbomer cement is not influenced by the absence of surface protection and that all test materials would exhibit a similar level of resistance against microleakage.

A possible limitation of the present study was that the study methodology attempted to simulate the oral condition as much as possible however, extracted teeth lack the pulp pressure and intertubular fluid pressure presents in the natural teeth in the oral cavity, which has influence on teeth moisture level affecting both microleakage and restoration-tooth interface. Moreover, restorative materials were placed in Class I cavities prepared using a carbide bur on extracted caries free molars. Although, clinically, Class I restorations are placed due to decay or carious lesions. Therefore, enamel/ dentin substrate characteristics in these situations may be different from the bonding substrates encountered in the in vitro study. In addition, being an in vitro study is also a drawback as the influence of the tooth brushing and dietary habits on the retention of these surface protective agents could not be assessed.

Within the limitations of this study, glass carbomer cement with protective surface coating had shown encouraging results. Therefore, it could be considered as an effective restorative material due to its better marginal seal with tooth structure than conventional GIC restorative materials. However, further clinical studies are necessary to determine its clinical performance and also required to elucidate the physical changes in glass carbomer cement, especially when the protective surface gloss is lost over time.

\section{CONCLUSION}

Surface coat when added to the glass carbomer cement yields less microleakage than the unsealed glass carbomer and conventional GIC.

\section{REFERENCES}

1. Batoni G, Pardini M, Giannotti A, Ota F, Giuca MR, Gabriele M, Campa M, Senesi S. Effect of removable orthodontic appliances on oral colonization by mutans streptococci in children. Eur J Oral Sci 2001; 109: 388-92.

2. Nikaido T, Moriya K, Hiraishi N, et al. Surface analysis of dentinal caries in primary teeth using a $\mathrm{pH}$-imaging microscope. Dent Mater J 2004; 23(4): 628-32.

3. Fuks AB. The use of amalgam in pediatric dentistry. Pediatr Dent 2002; 24: 448-55.

4. Dodes JE. The amalgam controversy. An evidence-based analysis. J Am Dent Assoc 2001; 132: 348-56.

5. Jackson RD, Morgan M. The new posterior resins and a simplified placement technique. J Am Dent Assoc 2000; 131: 375-83.

6. Donly KJ, García-Godoy F. The use of resin-based composite in children. Pediatr Dent 2002; 24: 480-8.

7. McLean JW. Clinical applications of glass-ionomer cements. Oper Dent 1992; 5: 184-90.

8. Simmons JJ. The miracle mixture. Glass ionomer and alloy powder. J Tex Dent 1983; 100: 6-12.

9. Beyls HM, Verbeek RM, Marten LC, Lemaitre L. Compressive strength of some polyalkenoates with or without dental amalgam alloy incorporation. Dent Mater 1991; 7: $151-4$.

10. Kerby RE, Bleihoder RF. Physical properties of stainlesssteel and silver-reinforced glass ionomer cements. J Dent Res 1991; 70: 1358-61.

11. Williams JA, Billington RW. Increase in compressive strength of glass ionomer cements with respect to time periods of 24 hours to four months. J Oral Rehabil 1991; 18: $163-8$.

12. Kramer N, Frankenberger R. Clinical performance of a condensable metal-reinforced glass ionomer cement in primary molars. Br Dent J 2001; 190: 317-21.

13. Cattani-Lorente MA, Dupuis V, Moya F, Payan J, Meyer JM. Comparative study of the physical properties of a polyacid-modified composite resin and a resin-modified glass ionomer cement. Dent Mater 1999; 15: 21-32. 
14. Wilson AD. Resin-modified glass ionomer cements. Int J Prosthodont 1990; 3: 425-9.

15. Xie D, Brantley WA, Culbertson BM, Wang G. Mechanical properties and microstructures of glass-ionomer cements. Dent Mater 2000; 16:129-38.

16. Woodfine B, Lancefield A. Modern glass ionomer meeting the amalgam ISO 1559 Challenge. The $81^{\text {st }}$ General Session of the International Association for Dental Research 2003; 25-8.

17. Ayad NM, El Negoly SA, Badie OM. An invitro study of the physic-mechanical properties of a new esthetic restorative versus dental amalgam. Rev Clin Psq Odontol 2008; 4: 137-44.

18. El-Negoly SA, Ibrahim FM, Ellatif AA. Immunohistochemical expression of tooth pulp dendritic cells as a response to ceramic reinforced glass ionomer restorative materials. Egypt Dent J 2009; 55: 93-102.

19. Deepa G, Shobha T. A clinical evaluation of two glass ionomer cemets in primary molars using atraumatic restorative treatment technique in india: 1 year follow up. Int $\mathrm{J}$ Paediatr Dent 2010; 20: 410-8.

20. Van Duinen RN, Davidson CL, De Gee AJ, Feilzer AJ. In situ transformation of glass-ionomer into an enamel-like material. Am J Dent 2004; 17: 223-7.

21. Cehreli ZC, Gungor HC. Quantitative microleakage evaluation of fissure sealants applied with or without a bonding agent: results after four year water storage in vitro. J Adhes Dent 2008; 10: 379-84.

22. Cehreli SB, Tirali RE, Yalcinkaya Z, Cehreli ZC. Microleakage of newly developed glass carbomer cement in primary teeth. Eur J Dent 2013; 7: 15-21.

23. Daniel W. Biostatistics. A foundation for analysis in health science $7^{\text {th }}$ ed. New York. Nijmegen, Netherlands: STI Book, 1999; 27-100.

24. Croll TP. Class I composite resin restoration. J Esthet Dent 1992; 4: 148-53.

25. Derkson GD, Richardson AS, Waldman RJ. Clinical evaluation of composite resin and amalgam posterior restoration. J Can Dent 1983; 4: 277-9.

26. Feilzer AJ, de Gee AJ and Davidson CL: Setting stresses in composites for two different curing modes. Dent Mater $1993 ; 9: 2-5$.

27. Muangmingsuk A, Senawongse P, Yudhasaraprasithi S. Influence of different soft start polymerization techniques on marginal adaptation of class V restorations. Am J Dent 2003; 16: 117-9.
28. Aboush YE, Jenkins CB. The effect of poly (acrylic acid) cleanser on the adhesion of glass polyalkenoate cement to enamel and dentin. J Dent 1987; 15: 147-52.

29. Wilson AD, Prosser HJ. A survey of inorganic and polyelectrolyte cements. Br Dent J 1984; 157: 449-54.

30. Haller B, Hofmann N, Klaiber B, Bloching U. Effect of storage media on microleakage of five dentin bonding agents. Dent Mater 1993; 91: 191-97.

31. Brackett W, Haisch L, Pearce M, Brackett M. Microleakage of class $\mathrm{v}$ resin composites placed with self-etching adhesives. J Prosthet Dent 2004; 91: 42-5.

32. Toledano M, Osorio E, Osorio R, Garcia-Godoy F. Microleakage of class $\mathrm{V}$ resin-modified glass ionomer and compomer restorations. J Prosthet Dent 1999; 81: 610-5.

33. Chan DC, Summitt JB, García-Godoy F, Hilton TJ, Chung KH. Evaluation of different methods for cleaning and preparing occlusal fissures. Oper Dent 1999; 24: 331-6.

34. Chen X, Cuijpers V, Fan M, Frencken JE. Marginal leakage of two newer glass ionomer-based sealant materials assessed using micro-CT. J Dent 2010; 38: 731-5.

35. Raskin A, Tassery H, D'hoore W, Gonthier S, Vreven Jm Degrange M, Dejaou J. Influence of the number of speciments on reliability of in vitro microleakage evaluations. Am J Dent 2003; 6: 207-10.

36. Parbhakar AR, Madan M, Rju OS. Marginal seal of flowable composites, injectable resin modified Glass Ionomer and composites in primary molars an in vitro study. J of Indian Society of Pedodontics and Preventive Dentistry 2003; 2: 21-5.

37. Kirkpatrick LA, Feeney BC. A simple Guide to IBM SPSS Statistics for version 20.0. (Student edn), Cengage Learning, Belmont, California; 2013.

38. Kotz S, Balakrishnan N, Read CB, Vidakovic B. Encyclopedia of statistical sciences. 2nd ed. Hoboken, N.J.: WileyInterscience; 2006.

39. Taylor MJ, Lynch E. Review microleakage. J Dent, 20: 3-10, 1992.

40. Mount GJ, Makinson OF. Glass ionomer restorative cements: clinical implications of the setting reaction. Oper Dent 1982; 7: 134-41.

41. Hotta M, Hirukawa H, Yamamoto K. Effect of coating materials on restorative glass ionomer cement surface. Oper Dent 1992; 17: 57-61. 